\title{
PERANCANGAN INSTALASI TATA UDARA RUANG BERSIH AREA PENIMBANGAN PADA INDUSTRI FARMASI KELAS E
}

\author{
Rudi Saputra ${ }^{1}$, Abdunnaser ${ }^{2}$ \\ Program Studi Teknik Mesin, Institut Sains dan Teknolodi Nasional, Jakarta ${ }^{1} 2$ \\ email ${ }^{1}$ : rudisaputra09@yahoo.com
}

\begin{abstract}
Cleanroom in the pharmaceutical industry is needed to eliminate a wide range of contamination, due to the room around the building materials, machinery equipment production, human and others generate millions of particles that can interfere with the quality of manufactured drugs. Cleanroom in the pharmaceutical industry is based on the ISO 14644-1 standard that is in a class of $E$ (100.000), which can be interpreted very clean conditioned room to awake from particles and microbial contamination. The number of particles in the $E$ (100.000) class at the size of 0,5 $\mu \mathrm{m}$ limited number of 3520000 particles $/ \mathrm{m}^{3}$ were obtained from the results of the design of 446771,3769 particles $/ \mathrm{m}^{3}$, for a particle size of $5 \mu \mathrm{m}$ particle number 29000 particles $/ \mathrm{m}^{3}$ is obtained by 47760,7813 partikel $/ \mathrm{m}^{3}$. Raw material weighing room temperature in the desain room $21^{\circ} \mathrm{C}$ and $40 \% \mathrm{RH}$, and the outside temperature is 32,72 ${ }^{\circ} \mathrm{C}$ and $72,77 \% \mathrm{RH}$. The results obtained design cooling load is 17329,077 Watt, with velocity distribution of air in the airway of $0,118 \mathrm{~m} / \mathrm{s}$ in air requirement of 99,615 l/s, so that the requirements for class E (100.000) according to ISO 14644-1 to the mixed flow of air velocity.
\end{abstract}

Keywords: Cleanroom, ISO 14644-1, particles.

\section{PENDAHULUAN}

Sistem Tata Udara adalah suatu sistem yang mengondisikan lingkungan melaui pengedalian suhu, Kelembaban nisbi, arah pergerakan udara dan mutu udara termasuk pengendalian partikel dan pembuangan kontaminan yang ada di udara. Sistem tata udara memegang peran penting dalam industri farmasi. Hal ini antara lain disebabkan karena untuk memberikan perlindungan terhadap lingkungan pembuatan produk, memastikan produksi obat yang bermutu, memberikan lingkungan kerja yang nyaman bagi personil dan memberi perlindungan pada lingkungan di mana terdapat bahan berbahaya melalui pengaturan sistem pembuangan udara yang efektif dan aman dari bahan tersebut.

Salah satu contoh sistem instalasi pengkondisian udara ruang bersih pada industri farmasi adalah ruang penimbangan bahan baku di pabrik PT. X yang terletak di daerah Kebayoran Lama Jakarta Selatan. Sistem pengkondisian udara ruang bersih pada ruang penimbangan bahan baku menggunakan mesin pendingin udara jenis Air Handling Unit (AHU).

Permasalahannya karena pengaruh kontaminasi dan pengendalian partikel serta pemborosan energy dan biaya. Sehingga bila suatu gedung akan dikondisikan dengan memasang sistem instalasi tata udara maka perlu diketahui terlebih dulu beban pendingin yang harus ditanggulangi dalam gedung tersebut, agar dapat dipilih peralatan yang tepat utuk dipasang sehingga tidak terjadi pemborosan energi dan biaya atau kemungkinan kurangnya kapasitas mesin yang dapat menyebabkan tidak tercapainya kondisi yang diinginkan.

Berdasarkan uraian tersebut maka pada kesempatan ini saya bermaksud membuat suatu perhitungan untuk mengatasi masalah perhitungan beban pendingin berdasarkan ketentuan standar ruang bersih (cleanroom) pada industri pembuat obat tersebut khususnya pada ruang penimbangan bahan baku.

\section{TINJAUAN PUSTAKA}

\section{Penjelasan umum ruang bersih}

Ruang bersih (cleanrooms) didefinisikan sebagai ruangan yang dibagun secara khusus, lingkungan yang mampu untuk dikendalikan secara tertutup. Dapat mengendalikan jumlah partikel di udara yang bersikulasi dalam ruanga. Ruang bersih mengontrol/mengendalikan temeperatur, kelembaban nisbi, tekanan udara, sirkulasi udara, gerakan udara, getaran, kebisingan, dan pencahayaan. Partikel yang dapat dikontrol termasuk jumlah partikel dan mikroba yang terkontaminasi dan konsentrasi jumlah partikel dan penyebabnya. 
Bagaimanapun ruang bersih adalah teknologi yang special yang dijelaskan pada Cara Pembuatan Obat yang Baik (CPOB):

Ruang atau area di bawah pengawasan dan pengendalian lingkungan terhadap cemaran partikulat dan mikroba pada tingkat yang telah ditetapkan. Kontruksi dan penggunaan area ini dibuat sedemiakian rupa untuk mengurangi masuknya, tumbuhnya dan tertahanya cemaran dalam ruang atau area.

Ruang bersih (cleanrooms) dapat dicapai dengan, pertama mensuplai udara dengan jumlah yang sangat besar yang telah disaring dengan filter berefisiensi tingkat tinggi. Udara dicairkan serta dihilangkan dari pertikel dan bakteri yang tersebar didalam ruangan yang dikondisikan dengan menggunakan berbagai alat pendukung pengkondisisan udara ruang bersih di dalam ruangan dan memberikan tekanan yang diinginkan kedalam ruangan dan memastikan agar tidak ada udara kotor yang dapat terdistribusi kedalam ruangan. Kedua, ruang bersih dibangun dengan bahan-bahan yang tidak menghasilkan partikel dan dapat dengan mudah dibersihkan.

\section{Aplikasi Ruang Bersih}

Ruang bersih (cleanrooms) sangat dibutuhkan pada berbagai macam aplikasi, dan karena manusia, mesin produksi, struktur bangunan tersebut menghasilkan kontaminasi. Terlebih manusia dan mesin produksi menghasilakan jutaan partikel. Umumnya penggunaan ruang bersih (cleanrooms) pada industri semikonduktor, pada dunia medis dan farmasi dibutuhkan untuk meniadakan mikro-organisme dan pertumbuhannya. Pada tabel 1 digambarkan kebutuhan ruang bersih (cleanrooms) pada berbagai macam industri.

Tabel 1 Kebutuhan Ruang Bersing (Cleanrooms)

Pada Industri

\begin{tabular}{|l|l|}
\hline \multicolumn{1}{|c|}{ Industri } & \multicolumn{1}{c|}{ Produk } \\
\hline Elektronik & Komputer, TV tabung, TV layar datar \\
\hline Semikonduktor & $\begin{array}{l}\text { Produk yang memiliki rangkaian yang terintergrasi, digunakan } \\
\text { pada memori kumputer dan aplikasi kontrol }\end{array}$ \\
\hline Mikromekanis & Gyroscopes, miniature bearings, CD \\
\hline Optik & Lensa, Fotografi, perlengkapan laser \\
\hline Bioteknologi & Berbagai macam produk antibiotic, genetika engeering \\
\hline Farmasi & Produk obat steril, obat-obat yang diminum atau disuntikan \\
\hline Peralatan Medis & Katup jantung, sistem by pass jantung \\
\hline $\begin{array}{l}\text { Makanan dan } \\
\text { Minuman }\end{array}$ & Produksi anggur, makanan dan minuman yang disterilkan \\
\hline
\end{tabular}

Sumber: W. Whyte, 2001, Cleanrooms Technology, Fundamental of Design, Testing and Operational

Pada saat ini banyak proses manufaktur membutuhkan ruang bersih (cleanrooms), dirancang untuk mampu mengendalikan partikel dan mikroba yang terkontaminasi dengan meninjau dari aspek instalasi dan biaya yang lebih ekonomis. Macammacam penggunaan ruang bersih (cleanrooms) dalam dunia manufaktur, pengemasan, ruang penelitian dan lain-lain.

\section{Klasifikasi Ruang Bersih (Cleanrooms) \\ Pembuatan Obat}

Ruang bersih (cleanrooms) dan sarana udara bersih diklasifikasikan sesuai dengan EN ISO 14644-1. Klasifikasi hendaklah dibedakan dengan jelas dari pemantauan lingkungan pada saat operasional. Jumlah maksimum partikulat udara yang diperolehkan untuk tiap kelas kebersihan diklasifikasikan menurut kelas seperti pada tabel 2.2. Kelas A, B, C dan D adalah kelas kebersihan ruang untuk pembuatan produk steril sedangkan kelas E adalah kelas kebersihan ruang untuk produk nonsteril.

Menurut standart ISO 14644-1 untuk menentukan klasifikasi batasan jumlah maksimum partikel $/ \mathrm{m}^{3}$ dalam ruang menggunakan persaman (2.1).

\section{Temperature dan kelembaban Relatif}

Besarnya temperature $(\mathrm{T})$ pada cleanrooms biasanya $20^{\circ} \mathrm{C}$ dengan kelembaban relative $(\mathrm{RH})$ $40 \% \pm 5 \%{ }^{4}$. Dan untuk daerah yang sensitive membutuhkan kelembaban relative $(\mathrm{RH})$ yang lebih rendah $25 \% \pm 5 \%$. Tingkatan tersebut juga tergantung dari lokasi geografis, produksi dan pakaian yang dikenakan. Dengan begitu temperature bola kering (DB) berkisar $18^{\circ} \mathrm{C}$ sampai $22^{\circ} \mathrm{C}$.

\section{Kebisingan}

Kebanyakan pada industri proses obatobatan aplokasi cleanrooms menimbulkan tingkat kebisingan yang tinggi dan volume suplai udara yang tinggi. Level yang diijinkan hamper mendekati 65 dBA untuk aliran udara searah dan setiap peralatan distribusi udara harus distandartkan. Untuk desain yang baik tingkat kebisingan $60 \mathrm{dBA}$ untuk kondisi tak terpakai.

\section{Getaran}

Mesin terpasang dengan compact, memberikan getaran langsung ke struktur pendukung. Bagaimanapun, dengan menggunakan penyangga, disebut getaran terhadap isolator antara mesin dengan struktur pendukung, besarnya getaran yang di transformasikan dapat berpengaruh. Penggunaan isolator terhadap pengaruh getaran dapat melindungi peralatan yang sensitiv terhadap dampak getaran.

\section{Diagram Psikometrik}

Didalam teknik pengkondisian udara, diagram psikometrik sangat bermanfaat sekali untuk dapat mengetahui secara cepat dan tepat tentang sifat thermodinamis udara basah. Sifat udara di atmosfir dikatakan basah karena merupakan suatu perpaduan antara udara kering $\left(\mathrm{N}_{2}, \mathrm{O}_{2}, \mathrm{Ar}, \mathrm{CO}_{2}\right)$ dengan uap air 
$\left(\mathrm{H}_{20}\right)$, dimana kandungan uap air pada udara hangat lebih banyak dari pada kandungan uap air pada udara dingin.

\section{METODE DAN PENGOLAHAN DATA Metode Perancangan}

Dalam menyelesaikan perancangan ruang bersih (cleanroom) ini, metode yang digunakan adalah studi literatur dengan mempelajari ilmu dan karya ilmiah yang berhubungan dengan ruang bersih (cleanroom). Data yang diolah didapat berdasarkan pengukuran langsung pada PT. X dan juga didukung dari data lingkungan yang didapatkan dari BMKG. Setelah data terkumpul penulis melakukan perancangan dalam upaya memenuhi tujuan dari penulisan ini.

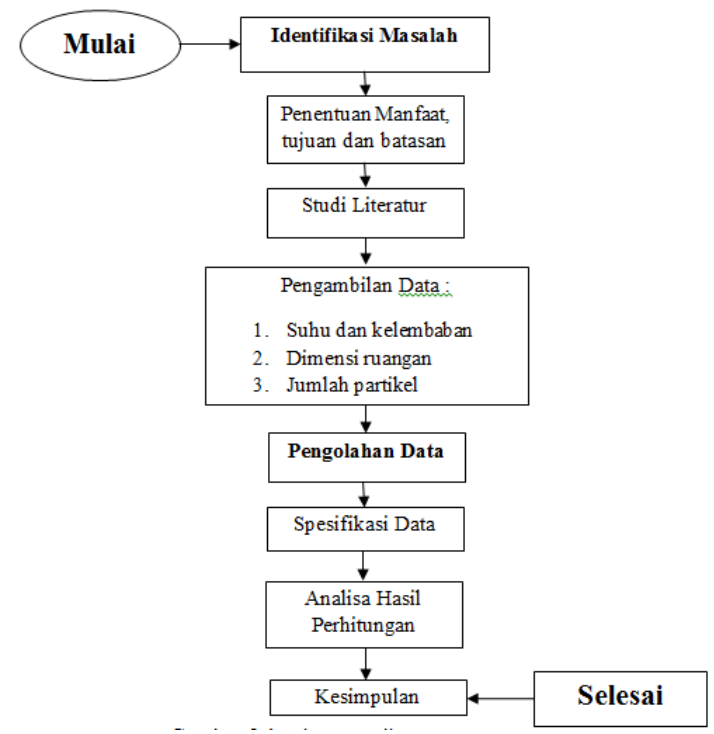

Gambar 1. Diagram Alir Perancangan

\section{Prosedur Pengambilan Data}

1) Pengukur temperature udara dan kelembaban relative adalah diletakkan di tempat yang rata, ditempelkan pada dinding atau menggunakan tempat yang sangat mudah untuk melakukan pengukuran pada area yang sulit dijangkau.

2) Pengukur jumlah partikel didalam ruangan diletakkan di tempat yang rata dan dengan ketinggian kurang lebih 1 meter.

3) Pengukuran geometri dilakukan agar mendapatkan beban yang akurat dalam mengkondisian ruangan. Untuk mengukur lebar, panjang dan tinggi ruangan.

\section{Peralatan Pengambilan Data}

Prosedur pengambilan data dilakukan di lapangan dengan melakukan pengukuran menggunakan alat ukur sebagai berikut:

1) ELPRO Ecolog TH1 alat pengukur temperature udara dan kelembaban relative

2) Handilaz mini PMS alat pengukur jumlah partikel
Meteran, digunakan untuk mengukur geometri ruangan

\section{Spesifikasi Data}

Temperatur, kelembaban dan Dimensi Ruangan

Tabel 2. Data Perancangan

\begin{tabular}{|l|l|}
\hline \multicolumn{2}{|c|}{ Data Perancangan } \\
\hline Lokasi & Kebayoran Lama Jakarta Selatan \\
\hline Letak Geografis & $6^{\circ} 14^{\prime} 6^{\prime \prime}$ Lintang Selatan 106 $46^{\circ} 1^{\prime \prime}$ Bujur Timur \\
\hline Fungsi Ruangan & Penimbangan \\
\hline Jadwal Kerja & $08.00 \mathrm{~s} / \mathrm{d} 17.00$ WIB \\
\hline Jumlah Kerja & 8 orang \\
\hline Temperatur Outdoor & $32,72^{\circ} \mathrm{C}$ \\
\hline Kelembaban Relativ & $73,77 \%$ \\
\hline Bulan Panas & Oktober (Menurut BMKG) \\
\hline Jam Panas & $12.00,13.00$ dan 14.00 \\
\hline
\end{tabular}

Data temperatur dan kelembaban relative diambil berdasarkan BMKG (Badan Meteorologi Klimatologi dan Geofisika).

Tabel 3. Data Pengukuran Geometri

\begin{tabular}{|c|c|c|c|c|c|}
\hline \multirow{2}{*}{$\begin{array}{c}\text { Nomor } \\
\text { Ruangan }\end{array}$} & \multicolumn{3}{|c|}{ Keterangan Geometri (m) } & Luas & Volume \\
\cline { 2 - 6 } & $\mathrm{P}$ & $\mathrm{L}$ & $\mathrm{T}$ & $\mathrm{m}^{2}$ & $\mathrm{~m}^{3}$ \\
\hline 1 & 1,92 & 1,57 & 2,71 & 3,01 & 8,17 \\
\hline 2 & 1,50 & 1,62 & 2,66 & 2,43 & 6,46 \\
\hline 3 & 1,50 & 1,64 & 2,54 & 2,46 & 6,25 \\
\hline 4 & 2,40 & 1,59 & 2,54 & 3,81 & 9,69 \\
\hline 5 & 2,60 & 1,38 & 2,70 & 3,59 & 9,69 \\
\hline 6 & 7,59 & 1,33 & 2,70 & 10,09 & 27,26 \\
\hline 7 & 3,10 & 1,40 & 2,62 & 4,34 & 11,37 \\
\hline \multicolumn{7}{|c|}{ Total } & 29,73 & 78,89 \\
\hline
\end{tabular}

Berdasarkan gambar diatas didapat ukuran ruangan seperti pada tabel 3, sedangkan pada tabel 4 didapat ukuran atap, dinding dan lain sebagainya.

Tabel 4. Data Pengukuran Geometri 2

\begin{tabular}{|c|c|}
\hline Nama & Luas $\left(\mathrm{m}^{2}\right)$ \\
\hline Atap, langit-langit dan lantai & 29,73 \\
\hline \multicolumn{2}{|l|}{ Dinding } \\
\hline Timur & 11,51 \\
\hline Barat & 11,29 \\
\hline Selatan & 20,24 \\
\hline Utara & 19,1 \\
\hline Jendela & 1,3 \\
\hline Pintu $2 \mathrm{~m} \times 0,7 \mathrm{~m}$, terdapat 8 buah pintu & 11,2 \\
\hline
\end{tabular}

\section{Perhitungan dan Perencanaan \\ Beban Pendingin}

Tabel 5. Beban Panas Latent

\begin{tabular}{|c|l|l|c|c|c|}
\hline \multirow{2}{*}{ No } & \multirow{2}{*}{ Item } & \multirow{2}{*}{ Keterangan } & \multicolumn{3}{|c|}{ (Watt) } \\
\cline { 4 - 6 } & & & 12 & 13 & 14 \\
\hline 1 & Pekerja & & 2400 & 2400 & 2400 \\
\hline 2 & Peralatan & $\begin{array}{l}\text { Timbangan } \\
\text { Analitik }\end{array}$ & 110 & 110 & 110 \\
\hline \multirow{2}{*}{} & & $\begin{array}{l}\text { Timbangan } \\
\text { Teknis }\end{array}$ & 176 & 176 & 176 \\
\hline & & $\begin{array}{l}\text { Timbangan } \\
\text { Elektronik }\end{array}$ & 198 & 198 & 198 \\
\hline 3 & & & 610,44993 & 610,44993 & 610,44993 \\
\hline \multicolumn{2}{|c|}{ Ventilasi } & & 3494,449 & 3494,449 & 3494,449 \\
\hline
\end{tabular}


Tabel 6. Total Beban Sensibel

\begin{tabular}{|c|c|c|c|c|c|}
\hline \multirow[t]{2}{*}{ No } & \multirow[t]{2}{*}{ Item } & \multirow[t]{2}{*}{ Keterangan } & \multicolumn{3}{|c|}{$\begin{array}{c}\mathrm{q} \\
\text { (Watt) }\end{array}$} \\
\hline & & & 12 & 13 & 14 \\
\hline 1 & Atap & & 2031,636 & 2261,981 & 2400,187 \\
\hline \multirow{7}{*}{2} & \multirow{4}{*}{ Partisi Dinding } & Selatan & 37,53457 & 37,53457 & 37,53457 \\
\hline & & Utara & 73,63428 & 73,63428 & 73,63428 \\
\hline & & Barat & 198,01034 & 198,01034 & 198,01034 \\
\hline & & Timur & 124,57172 & 124,57172 & 124,57172 \\
\hline & Partisi Langit-langit & & 5560,9843 & 5560,9843 & 5560,9843 \\
\hline & Partisi Lantai & & 1665,1139 & 1665,1139 & 1665,1139 \\
\hline & Partisi Pintu & & 52,1419 & 52,1419 & 52,1419 \\
\hline 3 & Jendela secara konduksi & & 624,3996 & 874,1594 & 874,1594 \\
\hline 4 & Penerangan & & 228 & 228 & 228 \\
\hline 5 & Pekerja & & 1240,8 & 1254 & 1267,2 \\
\hline \multirow[t]{3}{*}{6} & Peralatan & $\begin{array}{l}\text { Timbangan } \\
\text { Analitik }\end{array}$ & 104,5 & 105,6 & 105,6 \\
\hline & & $\begin{array}{l}\text { Timbangan } \\
\text { Teknis }\end{array}$ & 167,2 & 168,96 & 168,96 \\
\hline & & $\begin{array}{l}\text { Timbangan } \\
\text { Elektronik }\end{array}$ & 188,1 & 190,08 & 190,08 \\
\hline 7 & Ventilasi & & 888,42194 & 888,42194 & 888,42194 \\
\hline \multicolumn{3}{|c|}{ Total } & 13185,048 & 13683,193 & 13834,628 \\
\hline
\end{tabular}

Tabel 7. Total Panas

\begin{tabular}{|c|c|c|c|}
\hline \multirow{2}{*}{ Item } & \multicolumn{3}{|c|}{ q } \\
& \multicolumn{3}{|c|}{ (Watt) } \\
\cline { 2 - 4 } & 12 & 13 & 14 \\
\hline SH & 13185,048 & 13683,193 & 13834,628 \\
\hline LH & 3494,449 & 3494,449 & 3494,449 \\
\hline Total Heat & 16679,497 & 17177,642 & 17329,077 \\
\hline
\end{tabular}

\section{Jumlah Partikel}

Pada pengambilan sampel lokasi terkait jumlah partikel didalam ruangan, pada ukuran 0,5 $\mu \mathrm{m}$ dan $5 \mu \mathrm{m}$ bervolume 0.0056 liter dan 0.6837 liter dengan jumlah pengambilan sampel partikel yang ada didalam ruangan sebanyak 5 kali. Pengambilan dilakukan pada beberapa lokasi diantaranya: material dinding, material langit-langit, material lantai, pintu (antara ruang timbang dengan ruang bahan baku), dan pekerja. Jumlah pengambilan sampling partikel yang ada diruangan penimbangan di dokumentasikan pada tabel 8.:

Tabel 8. Jumlah Pengambilan Sampel Partikel

\begin{tabular}{|c|c|c|c|}
\hline \multicolumn{2}{|c|}{ Lokasi sampel } & \multicolumn{2}{c|}{ Jumlah partikel } \\
\cline { 3 - 4 } & $\mathrm{xi} \geq 0.5 \mu \mathrm{m}$ & $\mathrm{xi} \geq 5 \mu \mathrm{m}$ \\
\hline 1 & Infiltrasi pintu & 405000 & 41300 \\
\hline 2 & Langit-langit & 90400 & 6000 \\
\hline 3 & Dinding & 396000 & 36000 \\
\hline 4 & Pekerja & 430000 & 51600 \\
\hline 5 & Lantai & 218000 & 15900 \\
\hline
\end{tabular}

\section{Psycometric Prosces}

Sensible Heat Factor:
Dimana

$\begin{array}{ll}\mathrm{SH} & : \text { Sensible Heat } \\ \mathrm{TH} & : \text { Total Heat }=\mathrm{SH}+\mathrm{LH}\end{array}$

$$
S H R=\frac{S H}{T H}
$$

Pada tabel 7 besarnya panas sensible terbesar pada jam 14.00 yaitu 13834,628 Watt dan besarnya panas laten pada tabel 5 adalah 1094,449 Watt. Jam 14.00 adalah jam yang terpans diantara jam desain lainnya, memiliki nilai termal terbesar diantara jam desain lainnya.

Untuk menghitung besarnya sensible heat ratio adalah:

$$
\begin{gathered}
S H R=\frac{13834,628}{17329,077} \\
S H R=0,79
\end{gathered}
$$

Dengan mendapatkan nilai SHR, dengan menggunakan diagram psikometrik pada lampiran 1, maka temperature udara coil adalah $5{ }^{\circ} \mathrm{C}$. Untuk menghitung kebutuhan suplai udara dipilih sebagai jam panas untuk sensible heat total. Kebutuhan suplai udara total yang dibutuhkan untuk ruangan penimbangan bahan baku adalah:

Kebutuhan suplai udara:

$$
\frac{\text { Supply Air Flow }=}{\text { SH }}
$$

Dimana :

$\begin{array}{ll}\mathrm{T}_{\text {coil }} & : 5^{\circ} \mathrm{C} \\ \mathrm{T}_{\text {room }} & : 21^{\circ} \mathrm{C}\end{array}$

$$
\begin{array}{r}
\text { Supply Air Flow }=\frac{13834,628}{1,085 x(21-5)} \\
\text { Supply Air Flow }=796,925 \mathrm{l} / \mathrm{s}
\end{array}
$$

Untuk menghitung besarnya kelembaban ratio (RH) pada coil adalah :

$$
\begin{aligned}
& W_{s}=W_{R}-\frac{\mathrm{ql}}{3012 x \frac{\mathrm{L}}{\mathrm{S}}} \\
& W_{s}=0,0064-\frac{3494,449}{3012 \times 796,925} \\
& W_{s}=0,00145 \mathrm{~kg} / \mathrm{kg}
\end{aligned}
$$

Pada sistem distribusi udara, udara yang didistribusikan kedalam ruangan tidak 100\% udara luar ruangan akan tetapi besarnya udara yang di sirkulasikan (RA) adalah 80\% dan udara luar (OA) sebesar $20 \%$.

Untuk menghitung pada kondisi percampuran antara outside air (OA) dengan return air (RA) adalah:

$$
T_{M}=T_{R}+\frac{\frac{l}{S} \text { of } O A}{\operatorname{total} L / S}\left(T_{O A}-T_{R}\right)
$$


Besarnya temperature desain adalah $21^{\circ} \mathrm{C}$, jumlah udara luar yang masuk kedalam sistem (OA) sebesar $20 \%$ atau besarnya adalah 159,385L/s. Maka besarnya temperature udara campuran antara udara yang di sirkulasikan (RA) dengan udara luar yang masuk (OA) adalah:

$$
\begin{gathered}
T_{M}=21+\frac{159,385}{796,925}(33-21) \\
T_{M}=23,4 \stackrel{\circ}{\circ} \mathrm{C}
\end{gathered}
$$

Sistem udara yang dibuat pada ruangan penimbangan bahan baku mengacu pada rekomendasi Petunjuk Operasional Penerapan Pedoman Cara Pembuatan Obat yang Baik 2012, dengan prinsip percampuran udara yang di sirkulasikan (RA) dengan udara luar yang di bawah oleh sistem (OA).

Ditetapkan menurut perencanaan tata udara bahwa:
a) $\mathrm{Ra}=80 \%$

b) $\mathrm{Oa}=20 \%$

Maka, ditetapkan:

a) Supply Air (Sa) = 796,925 l/s

b) Outside Air (Oa) $=796,925 \times 20 \%=$ $159,385 \mathrm{l} / \mathrm{s}$

c) Return Air (Ra) = 796,925 x $80 \%=$ $637.54 \mathrm{l} / \mathrm{s}$

Sedangkan untuk menghitung besarnya pergantian udara perjam pada ruangan Penimbangan bahan baku adalah :

$$
\text { Pergantian udara }=\frac{\text { debit udara }}{\text { volume ruangan }}
$$

Debit udara : $796.925 \mathrm{l} / \mathrm{s}=2868.93 \mathrm{~m}^{3} / \mathrm{hour}$

Volume ruangan $\quad: 78,89 \mathrm{~m}^{3}$

$$
\text { Pergantian udara }=\frac{2868,93}{78,89}
$$

$$
\text { Pergantian udara }=36,36 \mathrm{ACH}
$$

\section{Saluran Udara Metode Equal Friction}

Dengan menggunakan metode equal friction pada ruang Penimbangan bahan baku, untuk mendapatkan kecepatan dan ukuran round duct serta squre duct menggunakan diagram friction losses dengan tekanan menurut handbook ASHRAE 1981, chapter 33-36. Dalam menentukan desain saluran diklasifikasikan berdasarkan low velocity dan high velocity, seperti pada penjelasan pada tabel 2 tentang desain cleanroom kelas E (100.000), dijelaskan bahwa industry farmasi ditentukan pola aliran udaranya adalah mixed. Ditentukan besarnya friction losses adalah $1,1 \mathrm{~Pa} / \mathrm{m}$.

Sedangkan untuk kebutuhan udara pada tiaptiap ruangan didapat dari total udara yang dibutuhkan ruangan Penimbangan bahan baku dibagi dengan jumlah ruangan yang akan didistribusikan, untuk udara buangan (exaust duct), saluran udara balik (return duct) dan saluran udara yang dibawa dari luar ruangan kedalam ruangan (outside air $d u c t$ ). Untuk kebutuhan udara pada tiap-tiap ruangan menggunakan prinsip yang sama. Saluran udara didesain dengan baik, dengan tujuan agar temperatur dan kelembaban ruangan yang didesain dapat terjaga dengan constant. Mampu dijaga agar partikel mampu untuk dikontrol serta dihilangkan dari sistem pengkondisian udara untuk ruangan Penimbangan bahan baku.

Setelah mendapatkan besarnya udara yang dibutuhkan pada tiap ruangan, dan besarnya friction losses yang telah ditentukan maka didapatkan besarnya kecepatan aliran pada setiap saluran udara dan besarnya ukuran diameter saluran udara. Pada gambar 2 mendeskripsikan desain sistem saluran udara pada ruangan Penimbangan bahan baku.

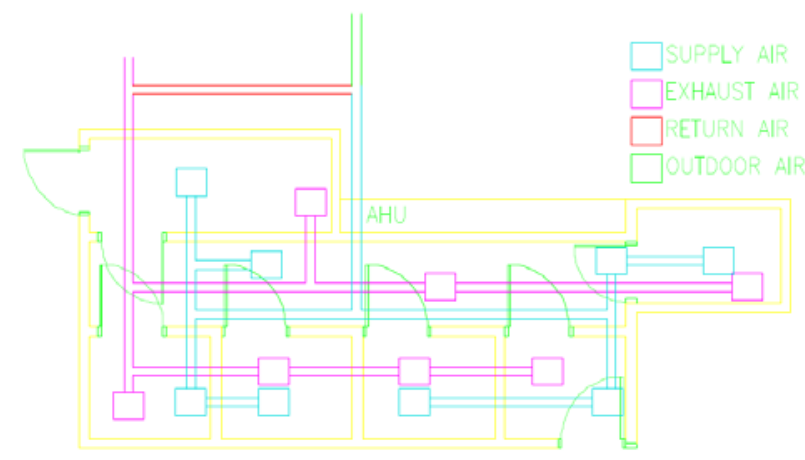

Gambar 2. Layout Sistem Saluran Udara Ruang Penimbangan

a) Supply Duct

Saluran distribusi udara untuk tiap-tiap ruangan dedesain berdasarkan gambar 2. terdapat berbagai macam saluran yang dimana titik $\mathrm{A}$ adalah AHU.

Kebutuhan total udara yang dibutuhkan pada ruangan Penimbangan bahan baku adalah 796,925 l/s, besarnya udara yang dibutuhkan adalah jumlah udara yang disupply ke setiap ruangan, berdasarkan ketentuan besarnya friction losses pada low velocity adalah $1,1 \mathrm{~Pa} / \mathrm{m}$. Maka didapat besarnya round duct A-B adalah $400 \mathrm{~mm}$ (15,7 inch) dan kecepatan saluran udara adalah $6,5 \mathrm{~m} / \mathrm{s}$ (lampiran 2) atau jika squre duct dengan ukuran 13 x 16 inch (lampiran 3).

Berdasarkan desain diatas maka didapatkan besarnya kecepatan aliran udara, diameter saluran udara (round duct) dan saluran udara kotak (squre $d u c t$ ), untuk mendapatkan melihat hasil selanjutnya dapat dilihat pada tabel 9. 
Tabel 9. Ukuran Ducting Supply

\begin{tabular}{|c|c|c|c|c|c|c|c|}
\hline $\begin{array}{c}\text { Saluran } \\
\text { Udara }\end{array}$ & $\begin{array}{c}\text { Air } \\
\text { Quality } \\
\mathrm{L} / \mathrm{s}\end{array}$ & $\begin{array}{c}\text { Friction } \\
\text { Losses } \\
\mathrm{Pa} / \mathrm{m}\end{array}$ & $\begin{array}{c}\text { Velocity } \\
\mathrm{m} / \mathrm{s}\end{array}$ & $\begin{array}{c}\text { Round } \\
\text { Duct } \\
\mathrm{mm}\end{array}$ & $\begin{array}{c}\text { Round } \\
\text { Duct } \\
\text { in }\end{array}$ & \multicolumn{2}{|c|}{$\begin{array}{c}\text { Squre Duct } \\
\text { in }\end{array}$} \\
\hline A-B & 796,925 & 1,1 & 6,5 & 400 & 15,7 & 13 & 16 \\
\hline B-C & 398,462 & 1,1 & 5,3 & 300 & 11,8 & 9 & 13 \\
\hline B-H & 398,462 & 1,1 & 5,3 & 300 & 11,8 & 9 & 13 \\
\hline C-D & 199,231 & 1,1 & 4,5 & 240 & 9,5 & 7 & 11 \\
\hline C-F & 199,231 & 1,1 & 4,5 & 240 & 9,5 & 7 & 11 \\
\hline H-I & 199,231 & 1,1 & 4,5 & 240 & 9,5 & 7 & 11 \\
\hline H-K & 199,231 & 1,1 & 4,5 & 240 & 9,5 & 7 & 11 \\
\hline D-E & 99,615 & 1,1 & 3,6 & 185 & 7,2 & 6 & 7 \\
\hline F-G & 99,615 & 1,1 & 3,6 & 185 & 7,2 & 6 & 7 \\
\hline I-J & 99,615 & 1,1 & 3,6 & 185 & 7,2 & 6 & 7 \\
\hline K-L & 99,615 & 1,1 & 3,6 & 185 & 7,2 & 6 & 7 \\
\hline K-M & 99,615 & 1,1 & 3,6 & 185 & 7,2 & 6 & 7 \\
\hline
\end{tabular}

b). Exhaust Duct

Digambarkan pada tabel 10 dan didapatkan besaran tersebut pada tabel 10, dengan menggunakan cara seperti pada menghitung ducting supply air.

Tabel 10. Ukuran Exhaust Duct

\begin{tabular}{|c|c|c|c|c|c|c|c|}
\hline $\begin{array}{c}\text { Saluran } \\
\text { Udara }\end{array}$ & $\begin{array}{c}\text { Air } \\
\text { Quality } \\
\mathrm{L} / \mathrm{s}\end{array}$ & $\begin{array}{c}\text { Friction } \\
\text { Losses } \\
\mathrm{Pa} / \mathrm{m}\end{array}$ & $\begin{array}{c}\text { Velocity } \\
\mathrm{m} / \mathrm{s}\end{array}$ & $\begin{array}{c}\text { Round } \\
\text { Duct } \\
\mathrm{mm}\end{array}$ & $\begin{array}{c}\text { Round } \\
\text { Duct } \\
\text { in }\end{array}$ & \multicolumn{2}{|c|}{$\begin{array}{c}\text { Squre Duct } \\
\text { in }\end{array}$} \\
\hline A-B & 99.615 & 1,1 & 3,6 & 185 & 7,2 & 6 & 7 \\
\hline D-C & 99.615 & 1,1 & 3,6 & 185 & 7,2 & 6 & 7 \\
\hline E-F & 99.615 & 1,1 & 3,6 & 185 & 7,2 & 6 & 7 \\
\hline H-I & 99.615 & 1,1 & 3,6 & 185 & 7,2 & 6 & 7 \\
\hline B-C & 199.2315 & 1,1 & 4,5 & 240 & 9,5 & 7 & 11 \\
\hline F-G & 199.2315 & 1,1 & 4,5 & 240 & 9,5 & 7 & 11 \\
\hline C-J & 398,462 & 1,1 & 5,3 & 300 & 11,8 & 9 & 13 \\
\hline G-I & 398,462 & 1,1 & 5,3 & 300 & 11,8 & 9 & 13 \\
\hline I-J & 597,693 & 1,1 & 5,9 & 360 & 14,2 & 12 & 14 \\
\hline J-K & 796,925 & 1,1 & 6,5 & 400 & 15,7 & 13 & 16 \\
\hline
\end{tabular}

\section{c).Return Air}

Kuantitas udara yang dikembalikan keladalam sistem adalah $80 \%$ dari total kebutuhan udara, atau jumlah udara yang dikembalikan kedalam sistem penagan udara untuk ruang Penimbangan bahan baku adalah 637,540 l/s. Dengan menggunakan perhitungan yang sama dalam menghitung kecepatan aliran dan round duct serta squre duct.

Kualitas udara 637,540 l/s, dan besarnya friction losses adalah 1,1, didapatkan menggunakan diagram aliran dan friction losses pada satuan SI, besarnya kecepatan $6,0 \mathrm{~m} / \mathrm{s}$ dan besarnya round duct adalah $365 \mathrm{~mm}$ atau 14,4 inch, dan untuk ukuran squre duct adalah $11 \times 16$ inch.

a) Outside Air Duct

Udara luar yang di input kedalam sistem adalah sebesar 20\% (Fress Air), atau udara luar yang di inputkan kedalam sistem pengkondisian udara sebesar 159,385 l/s. Maka besarnya kecepatan dan ukuran saluran udara, adalah: kecepatan udara 4,1 $\mathrm{m} / \mathrm{s}$ dan round duct $220 \mathrm{~mm}$ atau 8,6 inch dan untuk ukuran squre duct adalah 7 x 9 inch. Untuk dapat mellihat perhitungan kecepatan dan round duct dengan menggunakan diagram friction losses dengan air quality dapat dilihat pada lampiran 2, untuk melihat squre duct dapat dilihat pada lampiran 3.

\section{ANALISIS HASIL PERHITUNGAN}

Berdasarkan data yang diperoleh dan data yang dihitung untuk ruangan Penimbangan bahan baku pada bab sebelumnya, pada bab ini penulis akan menganalisa hasil dari pengolahan data tersebut.

\section{Beban Pendingin}

Dengan menggunakan data perancangan dan data pengukuran terhadap thermal dan geometri pada ruangan Penimbangan bahan baku, pada tabel 2, 3 dan 4 pada bab sebelumnya digunakan untuk perhitungan bebab pendingin. Segala bentuk mekanisme perpindahan panas yang dapat didistribusi kedalam ruangan dihitung agar mengetahui jumlah beban yang harus mampu dikonvesi menjadi dingin pada ruangan yang dikondisikan. Beban terdiri dari dua jenis sensible heat dan latent heat. Perhitungan beban pendingin mengacu pada ASHRAE. Setelah dihitung didapatkan beban pendingin, pada tabel 6 adalah total beban panas sensible yang bersumber dari eksternal dan juga internal.

Penggunaan material sangatlah berpengaruh dalam mendapatkan besarnya beban pendingin, dan penggunaan material juga diselektif agar nilai kontaminasi atau penyebaran partikel dapat diminimalisir.

Dalam melakukan perancangan, jam panas terdapat pada jam 14.00, dan bulan panas pada bulan Oktober diperoleh sensible heat pada jam 14.00 adalah 13834,628 Watt dapat dilihat pada table 6 . Begitu pula pada tabel 5 total latent heat, beban latent heat sebesar 3494,449 Watt. Dan diperoleh beban total (grand total heat) dari ruangan Penimbangan bahan baku adalah 17329,077 Watt.

\section{Jumlah Partikel}

Pada klasifikasi kelas dalam cleanroom, industri farmasi mengklasifikasikan jumlah partikel yang terdapat pada kelas E (100.000) pada ukuran partikel $0,5 \mu \mathrm{m}$ dengan jumlah maksimal 3520000 prtikel $/ \mathrm{m}^{3}$ dan ukuran partikel $5 \mu \mathrm{m}$ jumlah maksimal 29000 partikel $/ \mathrm{m}^{3}$. Dengan menggunakan persamaan (2.1) pada kelas E (100.000) untuk perhitungan jumlah partikel berdasarkan klasifikasi jumlah partikel didapatkan jumlah partikel pada ukuran $0,5 \mu \mathrm{m}$ dan $5 \mu \mathrm{m}$, jumlah partikel adalah $3516757 \mathrm{partikel} / \mathrm{m}^{3}$ dan 29251 partikel $/ \mathrm{m}^{3}$.

Pada persamaan (2.2) digunakan untuk menentukan jumlah pengambilan sampel partikel, ruangan Penimbangan bahan baku memiliki luas ruangan 29,73 $\mathrm{m}^{2}$ maka didapatkan jumlah pengambilan sampel sebanyak 5 kali. Setelah mendapatkan jumlah pengambilan sampel, dengan 
menggunakan persamaan (2.3) diperoleh volume pada tiap-tiap pengambilan sampel, untuk $0,5 \mu \mathrm{m}$ partikel volume pengambilan sampel sebanyak 0,0056 Liter sedangkan pada $5 \mu \mathrm{m}$ partikel volume pengambilan sampel sebanyak 0,6837 Liter. Dengan menggunakan persamaan (2.2) dan persamaan (2.3) pengambilan sampel dilakukan berdasarkan kemungkinan-kemungkinan sumber-sumber partikel dan kontaminasi partikel, seperti material bangunan, peralatan, pekerja dan infiltrasi yang terjadi. Didapatkanlah jumlah partikel $/ \mathrm{m}^{3}$ digambarkan pada gambar 3. Pengambilan sampel sebanyak 5 kali dengan volume yang sudah didapatkan pada masingmasing ukuran partikel.

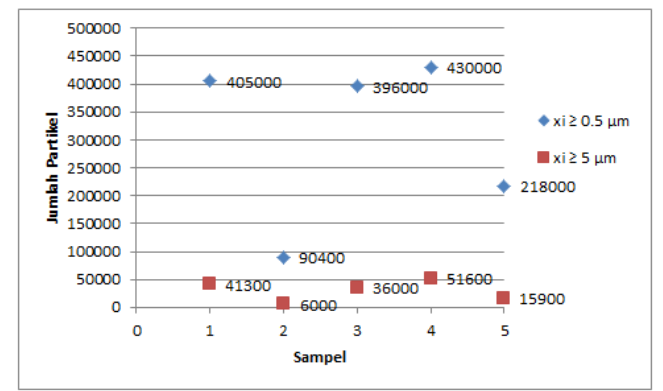

Gambar 3. Grafik Jumlah Partikel Ruangan Penimbangan

Menjelaskan dari gambar 3. pada pengambilan sampel pertama pada partikel $0,5 \mu \mathrm{m}$ dan $5 \mu \mathrm{m}$ adalah $405000 \mathrm{partikel} / \mathrm{m}^{3}$ dan 41300 partikel $/ \mathrm{m}^{3}$. Begitupun seterusnya sampai pada tahapan pengambilan sampel ke-lima pada partikel $0,5 \mu \mathrm{m}$ dan $5 \mu \mathrm{m}$ adalah $218000 \mathrm{partikel} / \mathrm{m}^{3}$ dan 15900 partikel/m³.

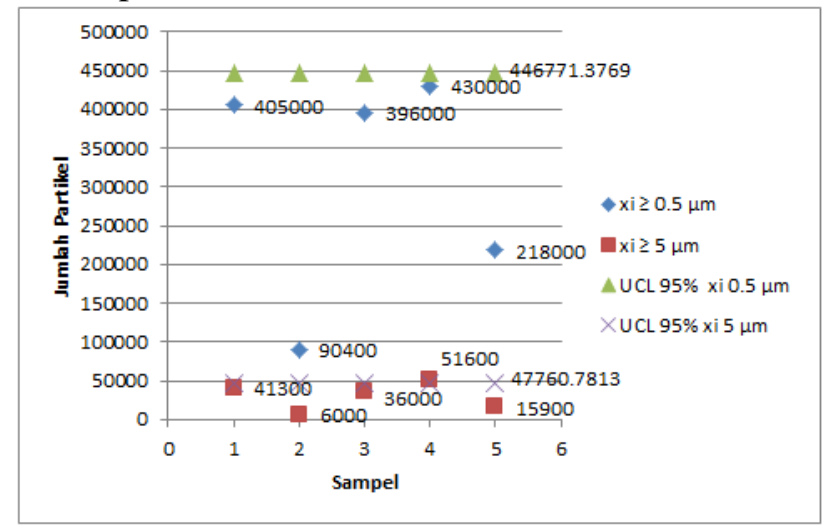

Gambar 4. Grafik Pengukuran Partikel Dan Pengukuran Partikel 95\% UCL

Setelah melakukan perhitungan berdasarkan jumlah partikel dilapangan menurut ISO 14644-1 maka didapatkan 95\% UCL (upper confidence limit), yaitu batas maksimal terhadap jumlah partikel pada ukuran $0,5 \mu \mathrm{m}$ dan $5 \mu \mathrm{m}$. Pada ukuran partikel $0,5 \mu \mathrm{m}$ batas atas berjumlah 446771.3769 partikel $/ \mathrm{m}^{3}$, sedangkan $5 \mu \mathrm{m}$ adalah sebesar 47760.7813 partikel $/ \mathrm{m}^{3}$. Diartikan bahwa UCL 95\% (upper confidence limit) pada tiap-tiap ukuran partikel membatasi jumlah maksimal partikel kurang dari nilai 95\% UCL, agar sistem pengkondisian udara terjaga kebersihannya, terjaga jumlah pertikelnya, terjaga suhu dan kelembabannya, terjaga pola aliran udaranya, terjaga tekanannya sesuai dengan klasifikasi ruang bersih (cleanroom) berdasarkan CPOB 2012. Dengan tujuan produk farmasi yang dihasilkan terhindar dari kontaminasi partikel, rentensi dan juga generasi pada partikel. Dan produk yang dihasilkan terjamin kualitasnya pada saat produksi, khususnya sampai pada tahapan sealing dan packing (atau tahapan pengemasan).

\section{Jumlah Partikel Terhadap Desain Temperatur dan Kelembaban Relativ}

Pada perencanaan ruangan Penimbangan bahan baku ruangan di desain pada temperatur $21^{\circ} \mathrm{C}$ dan RH 40\%. Menurut W. Whyte dalam bukunya Design Cleanroom pada perencanaan ruangan cleanroom untuk industri farmasi temperatur dan kelembaban ruangan $20{ }^{\circ} \mathrm{C}$ sedangkan untuk kelembaban $40 \% \pm$ 5\%. Pada kondisi udara yang didesain seperti ini diharapkan agar:

- Kenyamanan bagi pekerja

Manusia adalah sumber kontaminasi partikel yang paling mendominasi. Sehingga diperlukan udara yang baik, dan juga nyaman dimaksudkan untuk meminimalkan terjadinya kontaminasi yang diakibatkan oleh manusia. Tidak hanya pengkondisian udara tapi juga diperlukan alat pelindung diri lengkap guna mencegah terjadinya kontaminasi partikel.

- Produk yang dihasilkan

Dalam memproduksi obat-obatan diperlukan kelembaban yang sesuai dengan jenis obat yang direncanakan, khususnya untuk tipe obat yang diminum dan diinjeksikan. Karena obat dengan jenis yang disuntikan dan di injeksikan ke tubuh, jenis obatnya mudah untuk terkontaminasi dengan lingkungannya. Untuk mempertahankan mutu dari produk diperlukan udara yang sesuai dengan karakteristik obat, ruangan ini didesain untuk penimbangan bahan baku. Pada temperatur dan kelembaban yang di desain pada ruangan tersebut sesuai dengan kebutuhan ruangan tersebut.

Dengan perencanaan temperatur $21{ }^{\circ} \mathrm{C}$ dan kelembaban relative $40 \%$, diharapkan mampu untuk memenuhi persyaratan untuk ruangan Penimbangan bahan baku.

\section{Jumlah Partikel Terhadap Layout Ruangan}

Layout ruangan bersih adalah sarana untuk menentukan berbagai macam kebutuhan pada pengkondisian udara cleanroom. Pada ruangan ini layout dedesain agar mampu mempertahankan kebersihan ruangan. Pada ruangan 1 pada gambar 2 . adalah sistem airlock pada ruang antara untuk 
material yang masuk kedalam ruangan, langsung atau tidak langsung, saluran atau container yang bergerak dipersiapkan sedemikian rupa agar dalam keadaan bersih, terhindar dari partikel yang tidak diijinkan.

\section{Jumlah Partikel Terhadap Kecepatan Udara dan Pola Aliran Udara}

Jumlah partikel didalam ruangan juga bergantung dari kecepatan aliran udara, dari kecepatan udara pola atau bentuk dari aliran udara dapat diuraikan. Pada industri farmasi, diperlukan aliran udara dengan kecepatan turbulen. Dengan pola aliran udara mixed flow. Kecepatan aliran udara berkisar antara 0,051 m/s - 0,152 m/s.

Jika aliran udara sudah sesuai dengan standart, pada perancangan ini mengacu pada ISO 14644-1 maka penyebab terjadinya kontaminasi partikel serta penyebab-penyebab lain terhadap jumlah partikel dapat dicegah serta dijaga agar tetap bersih dan juga nyaman.

\section{Saluran Udara}

Pada pembahasan sebelumnya telah menghitung kecepatan serta ukuran dari tiap-tiap saluran udara untuk memenuhi kebutuhan ruangan Penimbangan bahan baku. Pada pebahasan ini akan digambarkan secara lebih detail terhadap kecepatan udara.

\section{1) Supply Air Duct}

Pada gambar 5. Menjelaskan tentang sistem distribusi aliran udara terhadap variable kecepatan dengan satuan SI. Gambar 5. Menjelaskan bahwa kecepatan udara yang dibutuhkan untuk memenuhi setiap ruangan pada ruangan Penimbangan bahan baku pada saluran utama adalah $6,5 \mathrm{~m} / \mathrm{s}$, sedemikian sehingga udara mengalir sampai pada titik F, G, J, L dan M kecepatan pada saluran udara berubah karena ada factor lain, khususnya dikarenakan perbedaan ukuran saluran udara. Saluran suplai sangat penting, dikarenakan udara yang dibutuhkan oleh setiap ruangan melalui saluran suplai udara.

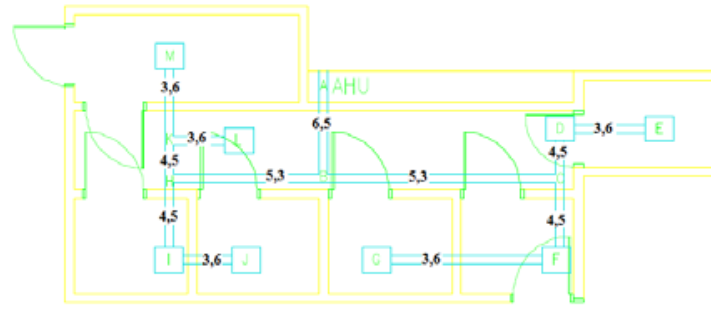

Gambar 5. Supply Air Duct Terhadap Kecepatan Aliran

\section{2) Exhaust Air Duct}

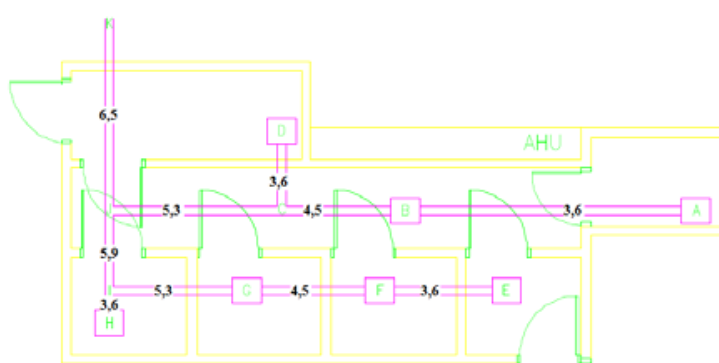

Gambar 6. Exhaust Air Duct Terhadap Kecepatan Aliran

Pada gambar 6. mendeskripsikan kecepatan udara pada saluran udara buang. Pada setiap ruangan udara yang masuk = udara yang keluar, berbanding terbalik dengan saluran suplai udara.

3) Return Air Duct dan Outside Air Duct

Pada sistem pengkondisian udara untuk ruangan Penimbangan bahan baku, udara yang dikembalikan kedalam sistem adalah sebesar $80 \%$ sedangkan udara yang bersih yang terbawa dari luar ruangan adalah sebesar $20 \%$.

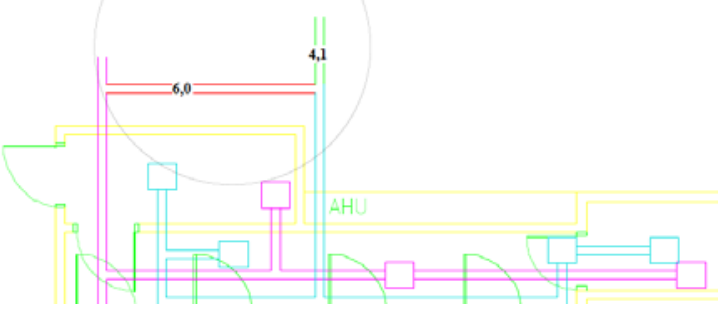

Gambar 7. Return Air Duct dan Outside Air Duct Terhadap Kecepatan Aliran

Pada gambar 7. warna hijau adalah udara luar yang akan masuk kedalam sistem sebesar 20\% dari total kebutuhan udara sehingga didapat kecepatan udara sebesar 4,1 m/s, untuk warna merah adalah udara yang disirkulasikan kembali kedalam sistem sebesar $80 \%$ memiliki kecepatan $6,0 \mathrm{~m} / \mathrm{s}$. Sehingga nanti udara yang masuk pada AHU adalah penjumlahan antara udara masuk (OA) dengan udara yang disirkulasikan kembali (RA), jumlah tersebut adalah sebesar 796,925 l/s dengan kecepatan udara sebesar $6,5 \mathrm{~m} / \mathrm{s}$.

Dibutuhkan aliran udara mixed flow untuk saluran supply udara pada tiap-tiap tuangan, adapun dalam menghitung kebutuhan udara ditinjau berdasarkan kecepatan pada saluran udara dengan geometri diffuser yang ada pada tiap-tiap ruangan.

\section{Pemilihan Filter}

Filter udara adalah komponen yang sangat penting dalam ruang bersih (cleanroom), filtr udara turut menentukan kualitas partikel pada ruang bersih (cleanroom). Target yang akan dicapai dalam desain ini adalah kelas E dalam CPOB 2012, adapun aliran udara ruangan yang didesain ini berjenis mixed flow. 
Seperti pada pembahasan sebelumnya dalam peranangan ruang bersih (cleanroom) untuk industri farmsi terdapat beberapa filter, prefiltera-filter-final filter. Dalam pemilihan tersebut menggunakan desain yang dimiliki oleh Camfil Farr, dimana terdapat 4 filter.

Adapun filter yang digunakan pada perencanaan ruangan untuk Penimbangan bahan baku adalah:

1) Prefilter G4 (M8)

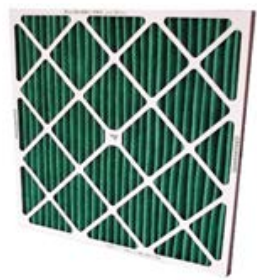

Gambar 8. Prefilter (30/30)

Keuntungan :

- Keuntungan mekanis yang tinggi

- Didukung oleh kisi-kisi filter yang sepenuhnya disuport dengan wire yang baik

- Rigid filter

- Permukaan filter yang luas

- Filter dibingkai untuk menghindari terjadinya bypass udara

2) Prefilter M6 (M11)

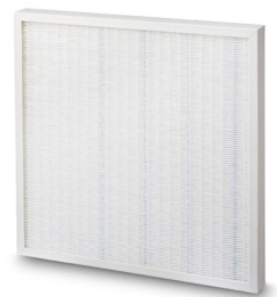

Gambar 9. Prefilter Ecopelat Grean

Keuntungan :

- Permukaan filter yang luas

- Tahan pada waktu operasi yang panjang

- Ultra compact dan ultra ligt

- Mampu bekerja dengan kondisi konstan

- Direkomendasikan oleh CREO

3) Filter F9 (M15)

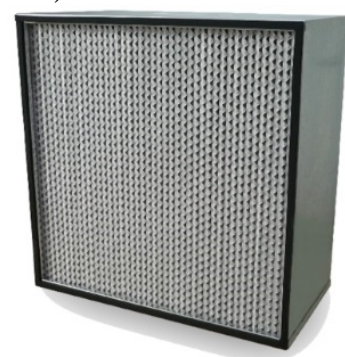

Gambar 10. Filter Airopac

Keuntungan :
- Penurunan tekanan rendah

- Permukaan filter yang luas

- Kapasitas menahan debu yang tinggi

- Bingkai logam yang kuat

- Konsep desain yang kaku

4) Final Filter (H14)

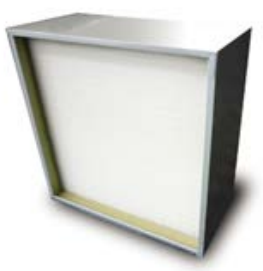

Gambar 11. Final Filter Absolute DE-H13

Keuntungan :

- Aplikasi aliran udara tinggi

- Media serat kaca berkualitas tinggi

- Efisiensi tinggi

- Fleksibilitas dalam ukuran

- H13 \& H14 secara individual di uji

\section{KESIMPULAN}

Dari hasil perancangan sistem instalasi tata udara ruang bersih (cleanroom) untuk ruang Penimbangan bahan baku pabrik farmasi dapat di kutip beberapa kesimpulan anrata lain, sebagai berikut:

1. Besarnya Toutdoor $32,72{ }^{\circ} \mathrm{C}$ dengan $\mathrm{RH}$ 73,77\%, sedangkan untuk Tindoor $21^{\circ} \mathrm{C}$ dan $\mathrm{RH}$ $40 \%$, dengan menggunakan diagram psikometrik didapat harga kelembaban outdoor $24,5 \mathrm{~g} / \mathrm{kg}$ sedangkan kelembaban indoor 6,5 $\mathrm{g} / \mathrm{kg}$, untuk harga entalpi outdoor $97 \mathrm{~kJ} / \mathrm{kg}$ dan entalpi indoor $38 \mathrm{~kJ} / \mathrm{kg}$, berdasarkan perhitungan jumlah panas (GTH) adalah 17329,077 Watt. Dengan menggunakan persamaan yang lain dan dengan bantuan diagram psikometrik didapat besarnya SHR (sensible heat ratio) adalah 0,79, sehingga didapatkan temperature pada coil adalah $5^{\circ} \mathrm{C}$.

2. Berdasarkan perhitungan jumlah partikel pada ruangan Penimbangan bahan baku menurut ISO 14644-1 pada ukuran partikel 0,5 $\mu \mathrm{m}$ jumlahnya sebesar 446771,3769 partikel $/ \mathrm{m}^{3}$ pada standart kelas E (100.000) partikel dibatasi pada jumlah 3520000 partikel $/ \mathrm{m}^{3}$, sedangkan pada ukuran partikel $5 \mu \mathrm{m}$ jumlahnya sebesar 47760,7813 partikel $/ \mathrm{m}^{3}$ pada standart dibatasi pada jumlah $29300 \mathrm{partikel} / \mathrm{m}^{3}$. Pada ruangan Penimbangan bahan baku jumlah maksimal partikel ukuran 0,5 $\mu \mathrm{m}$ dan $5 \mu \mathrm{m}$ mampu untuk dijaga agar terhindar dari berbagai macam kontaminasi.

3. Berdasarkan perhitungan didapatkan jumlah kebutuhan udara pada ruangan adalah 796,925 l/s, udara yang disirkulasikan kembali (RA) adalah 637,54 l/s, untuk udara yang baru (OA) 
adalah 159,385 1/s, dengan itu didapatkan besarnya pergantian udara minimal adalah sebesar $36,36 \mathrm{ACH}$.

4. Diperlukan distribusi udara yang besar untuk memenuhi kebutuhan udara, serta pola aliran udara mixed flow, berdasarkan perhitungan kecepatan udara yang didistribusikan kedalam ruangan adalah sebesar $0,1518 \mathrm{~m} / \mathrm{s}$.

5. Tipe unit mesin pendingin adalah

- AHU: dengan kapasitas, gran total heat sebesar 17329,077 Watt dan debit udara sebesar 2238,84 $\mathrm{m}^{3} /$ hour

- Filter: (1) Pre-Filter (30/30), (2) Ecopelat Grean, (3) Filter Airopac, (4) Absolute DEH13

\section{DAFTAR PUSTAKA}

Priyambodo, B. Manajemen Industri Farmasi, Global Pustaka Utama: Yogyakarta, 2007.

CPOB 2012, Penerapan Pedoman Cara Pembuatan Obat yang Baik, Badan POM RI, 2012.

ISO 14644-1: 1999 (E)

W. Whyte, Cleanrooms Technology, Fundamental of Design, Testing and Operational, John Wiley \& Sons Ltd, England, 2001.

ISO 14644, Cleanrooms and Associated Controlled Environments Part 1: Classification of air cleanliness byParticle concentration, 2015.

Ken Sutherland, Filters and Filtration Handbook, Burlington, USA, Elsevier LTD, 2008.

A Basic Design Guide for Cleanroom Applications, 2012

CPOB, Petunjuk Operasional Penerapan Pedoman Cara Pembuatan Obat yang Baik 2012 jilid 12, Badan POM RI, 2014.

Cleanroom Design, second editions, John Wiley \& Sons Ltd, England 1999

ISO 14644-4: 2001 (EN)

Ken. Sutherland, Filter and Filtration, Elsevier Ltd, UK, 2008

ASHRAE Hand Book, 2001

Life Sciences Industry Insights, Camfil Farr, 2011.

ASHRAE Standart 62-2001

ASHRAE Chapter 16 Ventilation and Infiltration, 2009

ASHRAE Chapter 26 Cooling Load, 1981

W. Rudoy: Cooling and heating load calculation manual (GRP 158, ASHRAE, 1997)

Smacna, Figure 14-2, Duct Friction Loss Chart (Metric Units), USA, 1990

https://onoe21.wordpress.com/laporanagroklimatologi-tentang-stasiunklimatologi/pengukuran-suhu-tanah/

ASHRAE Chapter 29 Nonresidental Cooling and Heating Load Calculation procedures, 2001

Psychrometry One of the Fundamental Series, Trane, 2012
Buchori, Luqman. Heat Transfer, Semarang, 2004

Ahmad Azis, Perancangan Instalasi Tata Udara Cleanrooms pada Industry Farmasi kelas 100, Jakarta, 2014 